Dialogic teaching and students' discursive identity negotiation in the learning of science

Kumpulainen, Kristiina

2017-04

Kumpulainen , K \& Rajala , A 2017 , ' Dialogic teaching and students' discursive identity negotiation in the learning of science ' , Learning and Instruction , vol. 48 , pp. 23-31 . https://doi.org/10.1016/j.learni

http://hdl.handle.net/10138/310081

https://doi.org/10.1016/j.learninstruc.2016.05.002

cc_by_nc_nd

acceptedVersion

Downloaded from Helda, University of Helsinki institutional repository.

This is an electronic reprint of the original article.

This reprint may differ from the original in pagination and typographic detail.

Please cite the original version. 


\title{
Dialogic teaching and students' discursive identity negotiation in the learning of science
}

\author{
Accepted to be published in Learning \& Instruction
}

Kristiina Kumpulainen and Antti Rajala, University of Helsinki

\begin{abstract}
This study sought to understand how dialogic teaching, as enacted in everyday classroom interaction, affords students opportunities for identity negotiation as learners of science. By drawing on sociocultural and sociolinguistic accounts, the study examined how students' discursive identities were managed and recognized in the moment and over time during dialogic teaching and what consequences these negotiations had for their engagement in science learning. The study used video data of classroom interactions collected from an elementary science learning project and placed a specific analytic focus on four students in particular. The results reveal evidence of a rich variety of discursive identities exposed during dialogic teaching, thus demonstrating how the students' identity negotiations were configured according to the social architecture of classroom discourse. Addressing the temporal dimension of dialogic teaching points out critical shifts in the students' discursive identities, of which identification is argued to be pivotal when creating equitable science learning opportunities.
\end{abstract}

\section{Introduction}

Dialogic modes of teaching and learning have attracted increased attention in science education as potential practices that afford students with greater authorship, meaning, and more equitable opportunities to learn (e.g., Resnick, Asterhan, \& Clarke, 2015). This is in contrast to narrow, authoritative, and impersonal approaches in which the classroom discourse does not allow for the bringing together and exploration of students' interests, concerns, and ideas. In dialogic teaching, Kumpulainen, K., \& Rajala, A. (in press). Dialogic teaching and students' discursive identity 1 negotiation in the learning of science. In C. van der Veen, \& B. van Oers (Eds.) Special issue: Classroom discourse and learning outcomes. Learning \& Instruction. 
the role of the teacher is to create an interactional space for students to talk and think together, creating an intersubjective orientation (cf., van der Veen, van Kruistum, \& Michaels, 2015) that support exploration of different views and understanding (cf., Nystrand, et al, 2003). The critical features typically associated with the dialogic approach to science education entail providing students with opportunities to negotiate their everyday and scientific reasoning, manage alternative viewpoints, appropriate the cultural norms and discourses of the discipline, and build positive personal dispositions and identities toward science (e.g., Kaartinen, \& Kumpulainen, 2002; Kumpulainen \& Lipponen, 2010; Mercer, Dawes, \& Kleine Staarman, 2009; Scott, Mortimer, \& Aquiar, 2006). These elements are becoming increasingly emphasized in the Finnish National Core Curriculum (FNBE, 2014) that, in addition to developing students' profound disciplinary knowledge (knowing what), addresses students' competences to learn to collaborate, negotiate, and build meaning and scientific knowledge (knowing how).

While ample research exists on dialogic teaching and learning (see, e.g., van der Linden, \& Renshaw, 2004; Resnick et al., 2015), less is known about how it defines the kinds of student identities it values, supports, and rejects in everyday science classroom interactions. Considering the efforts in Finland and more globally (cf. FNBE, 2014; OECD, 2008) to make science education meaningful to every student and to promote science learning as an inclusive social practice, this is arguably a serious limitation. The present study addresses this gap and underscores how researching identity is crucial for unpacking the complex relationship between classroom discourse and science learning. Consequently, this study seeks to understand how dialogic teaching, as enacted in everyday classroom interaction, creates opportunities for students' identity negotiation as learners of science. This is relevant in a time when science education is viewed as an equal right of, and necessity for, everyone (FNBE, 2014; Dumont, Istance, \& Benavides, 2010).

By drawing on sociocultural and sociolinguistic literature, this study holds that learning science is not simply a matter of conceptual acquisition but also concerns identity negotiation - that is, it affects who we are, who we like, how we are treated, and how we feel about ourselves and others as learners of science. A sociocultural perspective on identity diverges from essentialist 
perspectives that conceptualize identities as fixed, innate, and biologically determined as well as from constructivist perspectives that regard identities as arbitrary constructs (Francis, 2008). In contrast, identities are regarded as socially situated, mediated, and produced, as well as multiple and shifting (Wortham, 2003; Holland et al., 1998; Nasir \& Saxe, 2003). Furthermore, students' interests, attitudes, and motivation pertaining to science learning and how they respond to science education depend on the beliefs, values, and accepted identities of the cultural communities of which they are part (Lemke, 2001).

\subsection{Dialogic teaching and learning in science education}

Despite the potential of dialogic teaching in science education (e.g., Resnick et al., 2015), it also creates complex demands on teachers and students. For example, teachers often deal with tensions when providing diverse students with opportunities to explore various perspectives while maintaining sufficient control to achieve curriculum goals (Kovalainen \& Kumpulainen, 2005; Scott, Mortimer, \& Aquiar, 2006). For science learning to take place, dialogic teaching needs to provoke reasoned argumentation, critical analysis, and collective reflection (Mercer \& Howe, 2012). Moreover, educationally productive discourse requires establishing ground rules for social interaction, which demands systematic and longitudinal collective efforts (Mercer, 2008). A recent synthesis of empirical research on dialogic teaching concluded that it can potentially lead to enduring learning gains when it is adequately structured and when students are made accountable to shared standards of reasoning (Resnick et al., 2015).

Furthermore, asymmetries of participation can result in differences in learning opportunities and gains (Howe \& Abedin, 2013). Unequal opportunities to contribute to classroom interaction are dependent on the degree of inclusivity of the interaction patterns (Rajala, Hilppö, \& Lipponen, 2012; Kovalainen \& Kumpulainen, 2007); students' senses of competence and agency (Clarke, 2015); linguistic, gender, and ethnic identity dissonance (Brown, 2004; Brown, Reveles, \& Kelly, 2005; Gilbert \& Yerrick, 2001; Lee \& Fradd, 1998); and curriculum appropriateness (Rosebery, Warren, \& Conant, 1992).

Kumpulainen, K., \& Rajala, A. (in press). Dialogic teaching and students' discursive identity negotiation in the learning of science. In C. van der Veen, \& B. van Oers (Eds.) Special issue: Classroom discourse and learning outcomes. Learning \& Instruction. 
The research on classroom discourse and student identity in science education has similarly unpacked the mechanisms that create or hamper opportunities for engagement and learning. Brown (2004) showed how classroom discourse mediated whether ethnically diverse students could enact identities as learners of science. These students often rejected the use of scientific discourse, as they felt it conflicted with their identity (see also Brown et al., 2005). Furthermore, power relations shape students' identities as certain positions and discourses can be given statuses that are more privileged than others (Olitsky, 2007), such as privileging scientific jargon over non-technical language.

Overall, the research to date indicates that the social contexts of science classrooms mediate students' opportunities for identity development as learners of science (Olitsky, 2007; Silseth \& Arnseth, 2015). Students' identities are shaped as they negotiate goals, meanings, and roles within the science classroom (Varelas et al., 2007). To further address these findings, the present study points to the importance of researching the interactional contexts of science classrooms in the moment and across time, and how these contexts account for students' identity negotiation. The study also builds on the body of knowledge on this subject by contributing research on student identities during dialogic teaching to the existing research on students' identities in science education.

\subsection{Sociocultural and sociolinguistic approaches to classroom discourse, identity, and science} learning

The study is situated within sociocultural and sociolinguistic approaches that take social activity and discourse as core units of analysis (Cole, 1996; Gee, 1999, 2001; Vygotsky, 1962). The sociocultural approach holds that science learning is an interactional process in which social practices and artifacts create a shared semiotic system for joint participation, modes of thinking, and science learning (Kelly \& Chen, 1999). It emphasizes the importance of understanding science learning beyond conceptual acquisition in the development of identities (Kumpulainen $\&$ Renshaw, 2007). 
According to sociocultural theory, learning and identity development are intertwined. Learning transforms who we are and what we can do (Lave \& Wenger, 1991) while identity defines how we position ourselves and our actions. Identities are actualized and designated "stories" that we tell about ourselves and that others tell about us (Sfard \& Prusak, 2005). They are also performances that we enact as we interact with others (Holland, Lachicotte, Skinner, \& Cain, 1998). As people become more (or less) central members of a community, changes in identity accompany changes in position and status (Tan \& Barton, 2008). This, in turn, offers people new opportunities to engage with the ideas, constructs, processes, and artifacts that are available in the community. Thus, identity shifts are integrally related to knowledge shifts and together signify learning.

From a sociolinguistic perspective, in every discursive exchange participants co-construct meaning through interactions that position them as particular types of people (e.g., scientific, literate, competent, oppositional, etc.). Discourses offer students ways to use language to signal their identities to indicate group affiliation and cultural membership (Gumperz, 1982; Hymes, 1974; Gee, 1999, 2001). Participating in classroom interaction involves the negotiation of identities in consequential sociocultural contexts (Brown, 2004; Wortham, 2003). Therefore, the organization of classroom interaction and choices of discourse carry implications for how students and teachers perceive both each other and themselves.

In this study, the notion of discursive identity (Brown, 2004) serves as an analytic tool for understanding student identity negotiation in the dialogic teaching of science. The discursive identity model takes into account the sociocultural nature of learning and examines how learning offers students the potential to become certain people (Lave \& Wenger, 1991). This allows us to study how students' identities are negotiated over time through discourse, including antecedent histories, assumptions, and cultural knowledge (Mercer, 2008). From the perspective of discursive identity, identity construction is understood through an evaluation of how one signals identity in the moment, how those signals are interpreted and recognized over time, and how sociocultural contexts mediate this process (Brown et al., 2005). 


\subsection{Study}

In this study, we ask the following two questions:

- How are students' discursive identities negotiated, managed, and recognized in the moment and over time in the elementary science classroom during dialogic teaching?

- What opportunities and tensions emerge through dialogic teaching with regard to students' identity negotiation in the learning of science?

\section{Method}

\subsection{Empirical study}

The data were collected in a culturally and socioeconomically heterogeneous Finnish elementary classroom with 18 third-graders (nine girls and nine boys) aged nine to 10 years and their teacher (who is this paper's second author). The data used in this research were gathered during a semester-long (four-month) science learning project on the topic of forest. This topic is covered in the Finnish national core curriculum from an interdisciplinary perspective. The Forest Project was based on student-generated research questions. Taking into account the interdisciplinary and student-centered nature of the project, the teacher anticipated that the students would approach the forest from various perspectives.

The teacher had been influenced by dialogic approaches to teaching and learning, valuing classroom interaction that creates opportunities for students to share, comment, and build on each other's ideas, pose questions, and jointly construct new knowledge (see also O'Connor et al., this issue; van der Veen et al., this issue). In this classroom, "dialogic" is defined as an interactive space for negotiating difference and constructing new meanings (Wegerif, 2007). In addition to the teacher's overall interest in dialogic modes of teaching, he had also been inspired by the Thinking Together Project, which stresses the importance of ground rules for educationally productive interaction and learning (Dawes, Mercer, \& Wegerif, 2000). Accordingly, the classroom community had collectively formulated ground rules for their negotiation in the learning of science. In C. van der Veen, \& B. van Oers (Eds.) Special issue: Classroom discourse and learning outcomes. Learning \& Instruction. 
classroom interactions (e.g., everyone is listened to and acknowledged, everyone is helped when in need, and arguments are expected from everyone) to promote constructive and exploratory ways of using language as a social mode of thinking. Furthermore, in this classroom, both the teacher and students were held accountable for managing turn-taking during whole-class discussions.

The dialogic mode of teaching had already been implemented in this classroom for more than a year across the curriculum. Overall, this classroom community created a rich case (Mitchell, 1984) for investigating the construction of discursive identities in everyday, naturally evolving dialogic science teaching instead of drawing upon a researcher-designed study where pedagogical practices and subsequent interactions under investigation are novel to the participants. Moreover, we hold that to advance understanding of the conditions for the sustainable adoption of dialogic teaching practices it is important to investigate how teachers and students appropriate these practices while simultaneously attending to other concerns and demands stemming from their regular schoolwork (also see Kennedy, 2005).

The Forest Project began with a field trip to a nearby forest where the students took photos and created their own research questions on the topic. The students' questions included, for example, "Where do stones come from?", "What is made out of wood?", "Why are those stones in piles?", and "Why have trees fallen down?". The teacher organized the continuation of the project according to three themes based on his interpretation of the students' questions: Trees and Wood, Rocks and Stones, and the Ecology of a Forest. Figure 1 summarizes the phases and timeline of the Forest Project. 
Phase 1:

Formulating

research

questions on

the forest
Phase 2:

Trees and

Wood

Feb.13 - Mar. 12
Phase 3:

Rocks and

Stones

Mar. 18 - Apr.8
Phase 4:

Ecology of a

Forest

Apr.10 - May5

Figure 1. Forest Project phases

\subsection{Data collection and analysis}

The data used in this study consists of video-recorded whole-class discussions from the first three phases of the Forest Project (totaling 6 hours and 18 minutes of footage from 13 lessons); the fourth phase was excluded from the dataset since it was primarily a field trip with few instances of whole-class discussion.

The analysis proceeded as follows. Firstly, we watched and scrutinized the video data. The video-recordings were transcribed verbatim. Next, the video and transcripts were analyzed according to the thematic content and were divided into interactive episodes, constituting the unit of analysis (Linell, 1998). In this study, an interactive episode is defined as a thematically meaningful unit of interactional exchange. A new episode begins when the topic of discussion shifts. Each interactive episode analyzed conveys one topic that was brought under joint discussion by the teacher and/or students in the evolving classroom interaction.

Secondly, we selected four focal students, namely two girls and two boys, for closer analysis, using a purposeful sampling method to ensure maximum variation across the sample (Patton, 1990). Based on the preliminary viewing of the video data and the transcripts, we identified three key dimensions of variation in the students' discursive identity negotiations: (a) degree of cooperation/resistance, (b) use of everyday vs. scientific discourse, and (c) marginal vs. central Kumpulainen, K., \& Rajala, A. (in press). Dialogic teaching and students' discursive identity 8 negotiation in the learning of science. In C. van der Veen, \& B. van Oers (Eds.) Special issue: Classroom discourse and learning outcomes. Learning \& Instruction. 
participation. We selected students whose interaction gave clear evidence of difficulties in negotiating their discursive identities as learners of science as well as evidence of shifts through which these difficulties were, at least momentarily, overcome. The selection was finalized by identifying all interactional episodes in which the focal students participated, where explicit statements were made about these students, or where they were otherwise socially identified. In total, 285 episodes were analyzed pertaining to the four focal students, and the number of episodes ranged from 23 to 169 episodes per student (see Table 1).

Table 1. Focal students ${ }^{1}$

\begin{tabular}{|l|l|l|l|l|}
\hline Student & Oliver & Petra & Samira & Jimi \\
\hline Gender & Male & Female & Female & Male \\
\hline $\begin{array}{l}\text { No. of } \\
\text { interaction } \\
\text { episodes }\end{array}$ & 169 & 29 & 23 & 64 \\
\hline
\end{tabular}

Thirdly, we moved to a detailed analysis of the focal students' identity negotiations during dialogic teaching in science. Specifically, we traced how the students' discursive identities were constructed, disrupted, or stabilized in moment-to-moment interactions and over time.

Sociolinguistic discourse analysis served as the primary methodology for this (Brown, 2004;

Gee, 1999, 2001), focusing on the negotiation of identity domains in the moment and over time (Gee, 2001; Nasir \& Saxe, 2003). Gee (2001) proposed four domains in which identity is constructed through social interaction as people recognize and categorize each other. Namely, nature-identity (N-identity) — that is, how one's identity is determined by the characteristics that come to define an individual; institutional-identity (I-identity) — which is how one's identity is affirmed or defined through institutional means; discourse-identity (D-identity) — which reflects the relationship between the discourses that are used to define people; and affinity-identity (Aidentity) — which indicates membership in a shared set of cultural practices. In this study, these

\footnotetext{
${ }^{1}$ The students' names have been anonymized. Kumpulainen, K., \& Rajala, A. (in press). Dialogic teaching and students' discursive identity negotiation in the learning of science. In C. van der Veen, \& B. van Oers (Eds.) Special issue: Classroom discourse and learning outcomes. Learning \& Instruction.
} 
identity domains work together as a conceptual lens through which we derive meaning from the interaction data; thus, they should not be understood as exhaustive or mutually exclusive categories for analysis. The operationalization of our analysis of the students' discursive identities was developed through a dialogue between a grounded reading of the data and our analytic framework.

Finally, we synthesized the findings by constructing identity trajectories of the focal students' interactional engagement. The development of identity trajectories in the form of event maps allowed us to purposefully sample (Strauss \& Corbin, 1998) specific episodes representing significant evidence of the students' discursive identity negotiation in evolving classroom interactions. The data were analyzed by two researchers, first independently and then together, to establish joint agreement. Owing to the interpretative and contextual nature of the analysis, this procedure was found to be most appropriate for the rationale of this study.

\section{Results}

Next, we turn to illuminating our findings. We illustrate the interplay of varied discursive identities during dialogic science teaching and point out the key episodes through which the focal students' discursive identities were negotiated, marking shifts in their identities. The excerpts through which we demonstrate our findings were translated from Finnish into English. Standard punctuation was added for readability.

\subsection{Oliver}

Oliver inhabited several discursive identities that, at times, conflicted with the norms and ground rules of dialogic teaching in the classroom community. The most salient feature of Oliver's participation was a constant commentary on the classroom events during which he had achieved a discourse identity (D-identity) as a humorous person who made fun of himself, the teacher, or the other students, and elicited laughter from his fellow students. Oliver's interactional behavior also served to sustain an affinity-identity (A-identity) attached to an informal peer culture. negotiation in the learning of science. In C. van der Veen, \& B. van Oers (Eds.) Special issue: Classroom discourse and learning outcomes. Learning \& Instruction. 
Through exercising these discursive identities, Oliver recontextualized the classroom discussions as opportunities for joking, mockery, or testing the boundaries of what was acceptable. Further, at times Oliver explicitly criticized the teacher's framing of the science task, such as Oliver: That's so childish that nobody can remember it! (Episode 152). Oliver also challenged the rules that restricted movement in the physical classroom space by playing with his seat, moving around the class, or crawling on the floor (Episodes 68, 133, 159, 167, 170).

The teacher defined Oliver's actions as oppositional and often reprimanded him or threatened him with punishment. Oliver's identity as a disruptive student had been reified into a practice of daily formal evaluation of his behavior. The teacher also discussed his behavior in meetings with the school welfare team that considered Oliver to be at risk. Eventually this worry about Oliver culminated into an ADHD diagnosis. Oliver was assigned an institutional identity (I-identity) as an ADHD student. At the same time, this diagnosis served to create an interpretation of his misbehavior in terms of a neurological disorder ( $\mathrm{N}$-identity).

Despite these tensions between Oliver's discursive identities and the norms of dialogic teaching, our analysis revealed interactive episodes when Oliver took a more constructive role in the class discussions. The following excerpt demonstrates a shift that Oliver made from disruptively commenting on classroom events to actively contributing to joint meaning-making in science. In the excerpt, the class was discussing the different uses of paper in their everyday lives and by wider society. Before the excerpt commenced, Oliver had just indicated his willingness to be the chair, e.g., Oliver: I want to be the chair now (Episode 95). In fact, Oliver was keen to act in the roles made available by the dialogic teaching culture in this classroom, such as the scribe or the chair (Episodes 13, 15, 18, 29, 95, 111). In Excerpt 1, the teacher asked the students to comment on their initial ideas about trees, wood, and paper.

\section{Excerpt 1 (March 4, Episode 96)}

1. Teacher: So, well, are there other matters?

2. Oliver: Hik hik hik (raises his hand)

3. Teacher: Oliver

Kumpulainen, K., \& Rajala, A. (in press). Dialogic teaching and students' discursive identity 11 negotiation in the learning of science. In C. van der Veen, \& B. van Oers (Eds.) Special issue: Classroom discourse and learning outcomes. Learning \& Instruction. 
4. Oliver: I don't quite believe that paper can be used for interior decoration, so do people put paper on the floor, walls, ceiling, on the door, so that they do kind of...?

5. Teacher: Oliver is now the chair of this interior topic.

6. (voices in the background)

7. Oliver: Esa

8. Esa: That yellow since, oooh, wallpaper is paper.

9. Oliver: So you mean just ordinary paper.

10. Esa: Well, not just ordinary, like cardboard like.

11. Saara: Yes, walls can have posters, or paintings, so that picture is about paper.

12. Oliver: Not interior but...

13. Esa: Ah, like furniture.

14. Oliver: Yeah, like furniture, I meant.

Oliver bid for the floor (turn 2). However, he did not only raise his hand but also made nonsense "hik" sounds. At first, the teacher reprimanded him and threatened to send him out of the classroom but finally started ignoring the sounds. Making "hik" sounds can be interpreted as a way for Oliver to manage the interplay of his identities: as a constructive learner of science in the classroom, a humorous person joking about the classroom practices, and a member of a peer culture. While making "hik" sounds permitted Oliver to mock the classroom practice of bidding for the floor and waiting for permission to speak, he could also volunteer to contribute to the discussion.

The teacher gave Oliver a speaking turn, and Oliver contested one student's initial belief that paper can be used for furnishing (turn 4). Next, the teacher nominated Oliver to chair the discussion regarding the topic. What followed was a discussion (turnes 6-13) in which Oliver designated Esa and Saara to speak. Esa and Saara asserted that paper is used for furnishing. In the debate between Oliver, Esa, and Saara, different understandings of what the children meant by "paper" and "furnishing" were clarified. In line with his dialogical approach, the teacher sometimes refrained from evaluating the students' contributions and providing an expert view on the matter. He let the students debate among themselves about the disciplinary topic of societal 
and everyday uses of paper. Ideally, through participating in such a debate, the students could elaborate on a reasoned relationship between the subject and their lived experience (Fleer, 2015).

When acting as the chair, Oliver did not disrupt the lesson by engaging in his usual commentary but instead achieved an identity as an active contributor in joint meaning-making. Instead of just designating the next speakers, as was often the case with other students, he also commented on their contributions and brought the discussion forward. Thus, assuming the role of chair in association with dialogic teaching encouraged Oliver to take a more active role in joint meaningmaking.

\subsection{Petra}

Petra was a student who was formally identified with learning difficulties and low motivation for classroom learning activities. For these reasons, she regularly visited the special education teacher to receive additional support. She was formally diagnosed as a special needs student with a subjective right to extra educational services (I-identity).

Our analysis revealed distinct domains of Petra's discursive identities that were negotiated, contested, and enforced during the Forest Project. One of these involved the low volume of Petra's voice (N-identity), which was addressed regularly both by the teacher and her fellow students, making it a dominant identity for her. Moreover, while Petra was speaking, some students indicated their frustration, thus disturbing the lesson. The teacher attempted to manage the students' misbehaviors and to constructively support Petra in her participation by repeating what she wanted to say. He also tried to enforce appreciation of diversity in the classroom interaction, such as Teacher: So, we have different types of voices, so just try, and if we do not hear, I can repeat it (Episode 2).

A noticeable shift occurred in Petra's engagement that, at least momentarily, created a different discursive identity for her. This happened when Petra's question "Why do people cut trees down?" was recognized by the whole classroom community as a valid topic for joint discussion. negotiation in the learning of science. In C. van der Veen, \& B. van Oers (Eds.) Special issue: Classroom discourse and learning outcomes. Learning \& Instruction. 
In fact, a number of students wanted to contribute to this question, and it was referred to as “Petra's question" by many, such as Oliver: I have something to add to Petra's... (Episode 5). The teacher also took up Petra's question and used it to organize the focus of the subsequent joint discussion. This collective recognition of Petra's idea appeared to result in changes in her position and status, offering Petra a new discursive identity with which to engage in classroom interactions and in science learning (Episode 13).

The next excerpt illuminates the shift in Petra's discursive identity into an acknowledged and legitimate contributor in classroom interaction. Here, Petra brought up an emotional perspective on the collective discussion on trees as she explained how forests create joy and happiness in people's lives, and, for that reason, trees should not be cut down. Petra's emotional perspective to negotiating and making sense of science generated a lot of discussion (Episodes 5, 7, 13, 18, 21).

The negotiations and the students' differing opinions were now directed toward discussing forests and trees, not Petra's "voice identity". Petra's new position appeared to strengthen her affinity-identity (A-identity) — that is, belonging to the classroom community. The rich discussions over "Petra's question" expanded the framing of the discussion and, hence, Petra's contribution transformed into an artifact of collective negotiation and science learning. Here, trees and forests were examined from the perspective of the habitat as well as from emotional and aesthetic viewpoints, resonating with the interdisciplinary approach promoted in the Finnish curriculum that recognizes the human and social science perspectives in science teaching and learning (FNBE, 2014).

Excerpt 2 (March 19, Episode 14)

1. Maija: So if all trees were cut down there would be no forest.

2. Teacher: No trees, no forest, yes.

3. Jimi: Petra.

4. Petra: I think trees should not be cut down because that takes all the joy away.

5. Teacher: Takes away...

Kumpulainen, K., \& Rajala, A. (in press). Dialogic teaching and students' discursive identity 14 negotiation in the learning of science. In C. van der Veen, \& B. van Oers (Eds.) Special issue: Classroom discourse and learning outcomes. Learning \& Instruction. 
6. Petra: Joy.

7. Teacher: Aha.

8. Petra: When people go to the forest and if there are no trees, there will be no joy.

9. Teacher: Taking away the trees so that there would be no forest would take all the joy away from people?

10. Student (unable to identify which student): There would be nothing.

11. Teacher: Yep.

12. Kimmo: I meant it.

13. Teacher: Or was it Petra who said that this would take the joy away from people? So did you mean that the scenery would be boring or are there other reasons that joy may disappear?

14. Petra: No, the scenery would be boring since there is no joy; it would at least take my joy away.

15. Teacher: Well, Petra is the chair, yeah now some changes.

The episode began while Jimi was chairing the discussion and he gave Petra a turn (turn 3). In turn 4, Petra introduced an emotional perspective to her earlier question: "Why do people cut trees down?" by saying I think trees should not be cut down because that takes all the joy away. The teacher did not understand (or hear) Petra, and he asked what Petra meant by "takes away" (turn 5). Petra confirmed and completed the teacher's utterance by saying: ...joy. She further clarified her point in turn 8 by distancing herself from her earlier explanation and reasoned how people other than herself might not feel any joy if trees are cut down. The teacher reformulated Petra's reasoning (turn 9) to support joint negotiation, and some other students also joined in to confirm Petra's point (turns 10-12). In his next turn, the teacher emphasized Petra's contribution and invited her to reason further. He asked whether Petra thought it was boring scenery that caused people not to experience joy if the trees were cut, or whether there were other reasons (turn 13). In turn 14, Petra accepted the teacher's explanation and did not give other reasons. This may have been due to the teacher's closed question, which easily ends the discussion (Kumpulainen \& Wray, 2002). However, the discussion continued since the teacher granted Petra the role of chair. Petra accepted and started to grant turns to the other students, who 
continued to discuss other explanations for how cutting down trees would take joy away from people.

\subsection{Samira}

Samira was an immigrant student (I-identity) whose command of the Finnish language was developing. She received additional support from the school for her language acquisition. During the project, Samira's identity came to also be defined by her lack of contribution to joint discussions (D-identity). When she contributed, she mainly asked the teacher to clarify something, such as Teacher: Who has seen a wooden vase?; Samira: I don't even know what it is (Episodes 14; Episodes 20, 21, 29). The teacher defined the nature of Samira's engagement as passive and problematic - that is, as a failure to meet the expectations of dialogic teaching in this science classroom. Because Samira almost never volunteered to contribute to the discussions, the teacher repeatedly singled her out by specifically calling on her, such as Teacher: Samira, what happens to ice when ice starts to warm up? (Episode 25; Episodes 4, 6, 15, 22). Rather than encourage Samira, this appeared to discourage her from contributing.

The following excerpt further illuminates the tension between the nature of Samira's engagement and the teacher's expectation that everyone would actively contribute to classroom interactions. In the excerpt, the teacher told Samira what he wanted her to say in an attempt to make Samira take part in the discussion.

Excerpt 3 (February 8, Episode 10)

1. Teacher: And now hey, hey, hey, shh. Um, Roope you can be the chair soon; so now, um, Samira says now a comment from the teacher...

2. (Samira laughs)

3. Teacher: Samira, what is paper made with?

4. Samira: A paper machine.

Kumpulainen, K., \& Rajala, A. (in press). Dialogic teaching and students' discursive identity 16 negotiation in the learning of science. In C. van der Veen, \& B. van Oers (Eds.) Special issue: Classroom discourse and learning outcomes. Learning \& Instruction. 
5. Teacher: Paper machine; has anyone seen a paper machine? Roope is the chair.

The teacher first organized the discussion and informed the class that Samira would respond. Samira did as the teacher asked, but her laughter suggests that she expressed uneasiness with the position that the teacher was putting her in (turn 2). This interpretation is supported by Samira's comment earlier in the discussion after she had heard the teacher's request, Samira: This is ridiculous (Episode 9).

Notably, Samira only once auto-initiated her contribution to the classroom discussion during the Forest Project. This momentary and rare shift in Samira's participation occurred when her close friend, Maija, told the class about the cutting of trees in the neighborhood, and Samira spontaneously supported Maija's contribution; Maija: Near my yard they are making a kind of a tunnel through which you can get to the school faster, and there they have cut down all the trees; there was a forest; Samira: Yeah, there was (Episode 7). Although this brief episode does not allow for any deeper conclusions, it nevertheless indicates Samira's willingness to display a discourse-identity (D-identity) as a contributing student. Here, the interactional context giving rise to such behavior involved responding to a close friend's comment that resonated with Samira's everyday life and experiences. Overall, this observation confirms how the micromoments in the evolving classroom interactions both created and disclosed opportunities for the students' identity work as learners of science and are hence important to recognize in research and practice. It also demonstrates the challenge for dialogic teachers to be inclusive and respectful of each student's personalities.

\subsection{Jimi}

Jimi took an active role in classroom interaction by reasoning, explaining, and arguing using evidence. During the Forest Project, Jimi came to be recognized as a science expert (D-identity). He achieved this identity by displaying his extensive knowledge about the topics under discussion and drawing upon his large pool of relevant personal experiences. He also regularly 
deployed disciplinary and conceptual terminology and incipient disciplinary reasoning in his interactions (Episodes 7, 18, 19, 20, 21, 22, 23, 34, 36, 40, 42, 50, 52, 63).

The other students also reaffirmed Jimi's identity as an expert. For example, when the teacher asked whether any of them knew that when stones are heated they become liquid, Jimi was the only one who raised his hand (Episode 44). Another student, Kimmo, commented: "Jimi knew," suggesting that the class expected Jimi to know this. Jimi was positioned as a student who often knew more than the other students. As the project progressed, Jimi started to correct the teacher, as well (Episodes 29, 33, 36, 37). However, the following excerpt also shows how Jimi's use of scientific terminology created tensions between him and the other students who, in their interactions, positioned Jimi as different from the rest. This challenged Jimi's affinity-identity (A-identity) as a member of this classroom community. In the excerpt, the class was discussing the origins of stones. It began when Jimi commented on Kimmo's reasoning that little stones were formed when bits and pieces came off of the earth when meteors collided with it.

Excerpt 4 (February 8, Episode 7)

1. Jimi: (yawning, speaking unclearly) That stance is otherwise kind of quite reasonable, but how, for example, did the Himalayas, Mount Everest, and the Alps develop according to that theory? Mount Everest is one big mountain, and the Himalayas and Alps are huge mountain ranges.

2. Kasperi: What?

3. Kimmo: Could you clarify a bit?

4. Jimi: How could they have emerged?

5. Saara: Could you a speak a little bit about matters that are clear and make sense?

6. Pauliina: Teacher, why does no one comment on my questions?

7. Kasperi: (imitates Jimi's style of speaking)

8. Teacher: Hey, now, let's be polite. Kasperi, now you spoke really impolite to Jimi (the teacher points at Kasperi). Jimi was a bit tired, so Jimi spo- um, spoke spoke um for that reason sounded a bit unclear, so now you must apologize to Jimi, and Jimi had a great contribution, I...

9. (Jimi exits the classroom)

Kumpulainen, K., \& Rajala, A. (in press). Dialogic teaching and students' discursive identity 18 negotiation in the learning of science. In C. van der Veen, \& B. van Oers (Eds.) Special issue: Classroom discourse and learning outcomes. Learning \& Instruction. 
10. Teacher: Look at this now.

11. Kimmo: I apologized to him, but I did not understand much; I did not understand when he spoke about some colonel (“eversti” in Finnish); it wasn't really clear.

12. Student (unable to identify which student): Mount Everest

13. Teacher: Now go and get Jimi back here.

In turn 1, Jimi responded to Kimmo's reasoning. His contribution diverged substantially from the other students' discourses. Whereas the other students mostly used common reasoning and terminology, Jimi used scientific terminology such as "stance" and "theory" in reference to the contributions of the other students. Moreover, he explained how the Himalayas, Mount Everest, and the Alps connected to the concepts of mountains and mountain ranges, and challenged the others to explain how these could have emerged. Other students asked Jimi to clarify his contribution and criticized him for being unclear and not making sense (turns 2, 3, and 5). Kasperi mocked Jimi's manner of speaking by imitating him. The teacher noticed that Jimi got upset and scolded Kasperi for hurting Jimi's feelings. He urged Kasperi to apologize to Jimi and emphasized that Jimi had made a large contribution to the discussion. However, Jimi rushed out of the classroom. The teacher then accused the students of making Jimi upset. Kimmo defended himself and explained that he could not understand what Jimi was talking about. One of the students corrected Kimmo that Jimi’s contribution was about Mount Everest since Kimmo confused "Mount Everest" with "colonel" ("Mount Everest" and "eversti" in Finnish). The teacher then sent Kasperi and Kimmo after Jimi to apologize and to return him to class.

The teacher's mediation and reconciliation of the tension between disciplinary and everyday ways of speaking appeared to be crucial for supporting the development of Jimi's identity that involved the use of scientific forms of reasoning and discussion. Only after the teacher's explanation of how Jimi's contribution connected to what the class had been discussing did the other students join in to build on Jimi's contribution. Altogether, Jimi's example demonstrates the complexities of negotiating and managing the students' diverse discourses in dialogic teaching. Here, Jimi's discourse-identity (D-identity) as a competent user of scientific language created both tensions and opportunities for collective reasoning. The teacher's role as an negotiation in the learning of science. In C. van der Veen, \& B. van Oers (Eds.) Special issue: Classroom discourse and learning outcomes. Learning \& Instruction. 
intermediary between the students' various languages and maintenance of a respectful classroom climate was very important in order to turn Jimi's contributions into a collective resource for the whole classroom.

\section{Discussion}

The results of this study show how dialogic teaching and the underlying ground rules as enacted in this elementary science classroom created varied opportunities for the students' discursive identity negotiation. Moreover, addressing the temporal dimension of evolving classroom interaction throughout the science learning project highlights critical shifts in the students' discursive identities, thereby unpacking pivotal interactional mechanisms that supported and challenged opportunities for the students' identity negotiation in the learning of science.

Some of the discursive identities evidenced valued scientific literacy practices such as reasoning, explaining, and arguing using evidence, and drew upon a wealth of relevant personal experiences to make sense of science (Engle \& Conant, 2002; Herrenkohl \& Guerra, 1998). In addition, we identified the negotiation of contradicting institutional- and affinity-identities. Education has traditionally ignored, or sought to silence, everyday, informal discourses affiliated with the students' lives outside school, to the extent that they have remained hidden, sometimes only surfacing the students' disruptive interactions (Gutiérrez, Rymes, \& Larson, 1995; Rajala \& Sannino, 2015). During dialogic teaching, all these different discourses became alive and present.

Overall, dialogic teaching in this classroom made learning science open to diverse points of view and different discursive identities. Here, dialogic teaching was not about inviting students to elaborate on their everyday views in order to replace them later with the disciplinary views. Instead, respecting the students' perspectives and experiences was also about developing a dialogic stance to science in which various perspectives and views can inter-animate each other negotiation in the learning of science. In C. van der Veen, \& B. van Oers (Eds.) Special issue: Classroom discourse and learning outcomes. Learning \& Instruction. 
(Bakhtin, 1981). This approach is underscored in the Finnish National Core Curriculum that includes learning to deal with socio-scientific issues with others, such as negotiating the meaning of forests for nature, society and individuals. In this respect, the findings resonate with ongoing science reforms in Finland where efforts are being made to make science education responsive to diversity and more personally meaningful for all students (FNBE, 2014). The findings also connect with broad definitions of scientific literacy according to which science is not only about becoming a professional scientist but also about relating to the world as an engaged citizen (Roth \& Barton, 2004).

The temporal time-scale analysis revealed shifts in the nature of the classroom interaction that, at least momentarily, created different discursive identities for the students. The analysis points out how the social architecture of dialogic teaching both closed down and opened up opportunities for the students' identity negotiations as learners of science. For Oliver, the opportunity to act as the chair supported him in negotiating the contradictory demands embedded in his discursive identity as a member of an oppositional peer culture and an active contributor to the classroom discussion. For Petra, the opportunity to approach science learning from an affective perspective supported her in becoming recognized as a valued participant in joint meaning-making. For Samira, although mostly defined as a non-participating student, her discursive identity momentarily shifted when she was able to connect with another student's experience in science that she found meaningful. For Jimi, the teacher's interaction supported his identity as an expert when the teacher acted as a mediator between Jimi's use of scientific language and other students' understanding of Jimi's contributions. In sum, all these shifts underscore how the teacher's and students' co-construction of classroom discursive practices and norms can have a significant impact on how students develop their identities as learners of science. Moreover, these findings demonstrate the importance of the use and management of language and discourse for learning in science classrooms. It is therefore imperative to identify these identity shifts and to understand the social architecture underlying their emergence so as to support every student's engagement in science learning. 
The study also unpacks tensions in dialogic teaching and the students' identity negotiation as learners of science. These included tensions between the students' individual preferences for engagement in classroom interactions and collective engagement as regulated by shared ground rules, the use of common and formal discourses, and tensions between teaching and dialogue (see also Renshaw, 2004). Firstly, taking part in classroom interaction and following the ground rules of participation created tensions and the students often showed frustration with, and even resistance to, the classroom norms. For instance, Oliver and some other students made fun of the teacher and the classroom norms, and the teacher responded to these provocations with disciplinary actions. Secondly, the different discourses the students used to take part in classroom interactions created tensions for joint meaning-making, as demonstrated in Jimi's case. Interestingly, in this study it was not only the students' everyday language that was found problematic, but also the students' use of scientific language and terminology created tensions. Here, it was Jimi's scientific vocabulary that caused tensions in the classroom community since not all the students could follow such reasoning. Hence, the role of the teacher in supporting collective reasoning where everyday language and scientific language can be mutually beneficial is pivotal. Moreover, the teacher's role in supporting the establishment of a respectful and cohesive classroom culture where every student feels they belong seems important. Thirdly, the study identified tensions that were linked to the teacher's management of the balance between dialogue and teaching. In other words, the teacher's ability to follow the students' ideas and lines of reasoning and align them with academically valued discourses is important so that the power inherent in the formal language of the school's science curriculum could be both meaningful and accessible to students.

Taken together, the findings of this study point to the complexity of creating equitable science learning opportunities during dialogic teaching. Here, the classroom norms and ground rules of dialogic teaching, as well as the teacher's role, appear to be important and fragile. At worst, the teacher may even re-affirm students' marginal discursive identities, as was the case with Samira, when the teacher explicitly tried to invite her to contribute. The teacher's response to Samira's failure to contribute shows how dialogic teaching and its ground rules can work counterproductively and become a ritualistic aspect and a center of explicit attention, thus

Kumpulainen, K., \& Rajala, A. (in press). Dialogic teaching and students' discursive identity 22 negotiation in the learning of science. In C. van der Veen, \& B. van Oers (Eds.) Special issue: Classroom discourse and learning outcomes. Learning \& Instruction. 
distracting from the science learning itself. In effect, the acceptable institutional student identities in this classroom appeared to privilege those students who were active, reflective, and resourceful. Respectively, those students who were more observant and less contributory, conformist and/or disobedient were less valued. Rather than enforce a narrow student identity that everyone is expected to fit, sensitive guidance and open-mindedness is required from the teacher in order to make classroom interactions more inclusive of students' diverse identities (Kovalainen \& Kumpulainen, 2007). To this end, creating ground rules for dialogic teaching where students can flexibly move between peripheral and central participation becomes critical. Moreover, it is important that the ground rules are not imposed on students; instead, they should be open for continual negotiation and revision.

\subsection{Conclusion}

In summary, this study contributes to the body of research on dialogic teaching by demonstrating its unexplored possibilities and revealing tensions underlying students' discursive identity negotiations in the learning of science. Methodologically, the study demonstrates how focusing on the temporal dimension of students' participation in classroom interaction provides valuable insights for understanding how discursive identities emerge and are negotiated in interactive contexts, how these identities work as resources for communicating one's position, and as artifacts of collective interaction and learning for diverse students (Nasir \& Saxe, 2003). This information is pivotal for unpacking every student's opportunity for engagement and learning in dialogic teaching and supporting the development of their identities as learners of science.

\section{References}

Bakhtin, M. (1981). The dialogic imagination. Four essays by M. M. Bakhtin. University of Texas Press.

Brown, B. (2004). Discursive identity: Assimilation into the culture of science classroom and its implications for minority students. Journal of Research in Science Teaching, 41(8), 810-834. negotiation in the learning of science. In C. van der Veen, \& B. van Oers (Eds.) Special issue: Classroom discourse and learning outcomes. Learning \& Instruction. 
Brown, B. A., Reveles, J., \& Kelly, G. (2005). Scientific literacy and discursive identity: A theoretical framework for understanding science learning. Science Education, 89(5), 779-802.

Clarke, S. (2015). The right to speak. In L. Resnick, C. Asterhan, \& S. Clarke (Eds.), Socializing intelligence through academic talk and dialogue (pp. 167-180). Washington, DC: AERA.

Cole, M. (1996). Cultural psychology: A once and future discipline. Cambridge, MA: Harvard University.

Dawes, L., Mercer, N., \& Wegerif, R. (2000). Thinking together: A programme of activities for developing thinking skills at KS2. Birmingham: The Questions Publishing.

Dumont, H., Istance, D., \& Benavides, F. (2010). The nature of learning. Using research to inspire practice. France: OECD Publishing.

Engle, R., \& Conant, F. (2002). Guiding principles for fostering productive disciplinary engagement: Explaining an emergent argument in a community of learners classroom. Cognition and Instruction, 20(4), 399-483.

Fleer, M. (2015). Imagination and its contributions to learning in science. In M. Fleer \& N. Pramling (Eds.), A Cultural-Historical Study of Children Learning Science (pp. 39-57). Netherlands: Springer.

FNBE (2014). Perusopetuksen opetussuunnitelman perusteet 2014 [National Core Curriculum for Basic Education 2014] http://www.oph.fi/ops2016/perusteet

Francis, R. (2008). The Predicament of the Learner in the New Media Age: an investigation into the implications of media change for learning. $\mathrm{PhD}$ dissertation. University of Oxford.

Gee, J. (1999). An introduction to discourse analysis: Theory and method. London: Routledge.

Kumpulainen, K., \& Rajala, A. (in press). Dialogic teaching and students' discursive identity 24 negotiation in the learning of science. In C. van der Veen, \& B. van Oers (Eds.) Special issue: Classroom discourse and learning outcomes. Learning \& Instruction. 
Gee, J. (2001). Identity as an analytic lens for research in education. Review of Research in Education, 25, 99-125.

Gilbert, A., \& Yerrick, R. (2001). Same school, separate worlds: A sociocultural study of identity, resistance, and negotiation in a rural, lower track science classroom. Journal of Research in Science Teaching, 38, 574-598.

Gumperz, J. (Ed.). (1982). Language and social identity. Cambridge, UK: Cambridge University Press.

Gutiérrez, K., Rymes, B., \& Larson, J. (1995). Script, counterscript, and underlife in the classroom: James Brown versus Brown v. Board of Education. Harvard Educational Review, $65(3), 445-472$.

Herrenkohl, L., \& Guerra, M. (1998). Participant structures, scientific discourse, and student engagement in fourth grade. Cognition and Instruction, 16(4), 431-473.

Holland, D., Lachiocotte, W., Skinner, D., \& Cain, C. (1998). Identity and agency in cultural worlds. Cambridge, MA: Harvard University Press.

Howe, C., \& Abedin, M. (2013). Classroom dialogue: A systematic review across four decades of research. Cambridge Journal of Education, 43(3), 325-356.

Hymes, D. (1974). Foundations of sociolinguistics: An ethnographic approach. Philadelphia, PA: University of Pennsylvania.

Kaartinen, S., \& Kumpulainen, K. (2002). Collaborative inquiry and the construction of explanations in the learning of science. Learning and Instruction, 12(2), 189-212.

Kumpulainen, K., \& Rajala, A. (in press). Dialogic teaching and students' discursive identity 25 negotiation in the learning of science. In C. van der Veen, \& B. van Oers (Eds.) Special issue: Classroom discourse and learning outcomes. Learning \& Instruction. 
Kelly, G., \& Chen, C. (1999). The sound of music: Constructing science as sociocultural practices through oral and written discourse. Journal of Research in Science Teaching, 36(8), 883-915.

Kennedy, M. (2005). Inside teaching: How classroom life undermines reform. Cambridge, MA: Harvard University Press.

Kovalainen, M., \& Kumpulainen, K. (2005). The discursive practice of participation in an elementary classroom community. Instructional Science, 33(3), 213-250.

Kovalainen, M., \& Kumpulainen, K. (2007). The social construction of participation in an elementary classroom community. International Journal of Educational Research, 46(3), 141158.

Kumpulainen, K., \& Lipponen, L. (2010). Productive interaction as agentic participation in dialogic enquiry. In K. Littleton \& C. Howe (Eds.), Educational dialogues. Understanding and promoting productive interaction (pp. 48-63). London: Routledge.

Kumpulainen, K., \& Renshaw, P. (2007). Cultures of learning. International Journal of Educational Research, 46(3), 109-115.

Kumpulainen, K. \& Wray, D. (2002). Classroom interaction and social learning. From theory to practice. London: Routledge Falmer.

Lave, J., \& Wenger, E. (1991). Situated learning: Legitimate peripheral participation. Cambridge: Cambridge University Press.

Lee, O., \& Fradd, S. (1998). Science for all, including students from non-English-language backgrounds. Educational Researcher, 27(4), 12-21.

Kumpulainen, K., \& Rajala, A. (in press). Dialogic teaching and students' discursive identity 26 negotiation in the learning of science. In C. van der Veen, \& B. van Oers (Eds.) Special issue: Classroom discourse and learning outcomes. Learning \& Instruction. 
Lemke, J. (2001). Articulating communities: Sociocultural perspectives on science education. Journal of Research in Science Teaching, 38(3), 296-316.

Linell, P. (1998). Approaching dialogue: Talk, interaction and contexts in dialogical perspectives. Amsterdam: John Benjamins.

Mercer, N. (2008). The seeds of time: Why classroom dialogue needs a temporal analysis. The Journal of the Learning Sciences, 17(1), 33-59.

Mercer, N., \& Howe, C. (2012). Explaining the dialogic processes of teaching and learning: The value and potential of sociocultural theory. Learning, Culture and Social Interaction, 1(1), 1221.

Mercer, N., Dawes, L., \& Kleine Staarman, J. (2009). Dialogic teaching in the primary science classroom. Language and Education, 23(4), 353-369.

Mitchell, C. (1984). Typicality and the case study. In R. Ellens (Ed.), Ethnographic research: A guide to general conduct (pp. 238-241). New York: Academic Press.

Nasir, N., \& Saxe, G. (2003). Ethnic and academic identities: A cultural practice perspective on emerging tensions and their management in the lives of minority students. Educational Researcher, 2(5), 14-18.

Nystrand, M., Wu, L. L., Gamoran, A., Zeiser, S., \& Long, D. A. (2003). Questions in Time: Investigating the Structure and Dynamics of Unfolding Classroom Discourse. Discourse Processes, 35(2), 135-198.

OECD (2008). Encouraging student interest in science and technology studies: Global Science Forum. Paris: OECD. 
Olitsky, S. (2007). Facilitating identity formation, group membership, and learning in science classrooms: What can be learned from out of field teaching in an urban school. Science Education, 91(2), 201-221.

Patton, M. (1990). Qualitative evaluation and research methods. Beverly Hills, CA: Sage.

Rajala, A., Hilppö, J., \& Lipponen, L. (2012). The emergence of inclusive exploratory talk in primary students' peer interaction. International Journal of Educational Research, 53, 55-67.

Rajala, A. \& Sannino A. (2015). Students' deviations from a learning task: An activity theoretical analysis. International Journal of Educational Research, 70, 31-46.

Resnick, L., Asterhan, C., \& Clarke, S. (Eds.). (2015). Socializing intelligence through academic talk and dialogue. Washington, DC: AERA.

Roth, W.-M., \& Barton, A. C. (2004). Rethinking scientific literacy. New York: Routledge Falmer.

Rosebery, A., Warren, B., \& Conant, F. (1992). Appropriating scientific discourse: Findings from language minority classrooms. The Journal of Learning Sciences, 2(1), 61-94.

Scott, P. H., Mortimer, E. F., Aguiar, D. G. (2006). The tension between authoritative and dialogic discourse: a fundamental characteristic of meaning making interactions in high school science lessons. Science Education, 90(3), 605-631.

Sfard, A., \& Prusak, A. (2005). Telling identities: In search of an analytic tool for investigating learning as a culturally shaped activity. Educational Researcher, 34(4), 14-22.

Silseth, K. \& Arnseth, H-C. (2015). Frames for learning science: Analyzing learner positioning in a technology-enhanced science project. Learning, Media and Technology. DOI: $10.1080 / 17439884.2015 .1100636$

Kumpulainen, K., \& Rajala, A. (in press). Dialogic teaching and students' discursive identity 28 negotiation in the learning of science. In C. van der Veen, \& B. van Oers (Eds.) Special issue: Classroom discourse and learning outcomes. Learning \& Instruction. 
Strauss, A., \& Corbin, J. (1998). Basics of qualitative research: Techniques and procedures for developing grounded theory (2nd ed.). Thousand Oaks, CA: Sage.

Tan, E., \& Barton, A. (2008). From peripheral to central, the story of Melanie's metamorphosis in an urban middle school science class. Science Education, 92(4), 567-590.

van der Linden, J. \& Renshaw, P. (Eds.) (2004). Dialogic learning: Shifting perspectives to learning, instruction, and teaching. London: Kluwer.

van der Veen, C., van Kruistum, C., \& Michaels, S.(2015). Productive Classroom Dialogue as an Activity of Shared Thinking and Communicating: A Commentary on Marsal. Mind, Culture, and Activity, 22(4), 320-325, DOI: 10.1080/10749039.2015.1071398

Varelas, M., Pappas, C. , Tucker-Raymond, E., Arsenault, A., Ciesla, T., Kane, J., Kokkino, S., \& Siuda, J. E. (2007). Identity in activities. In W. Roth \& K. Tobin (Eds.), Science, learning, and identity: Sociocultural and cultural historical perspectives (pp. 203-242). Rotterdam: Sense Publishers.

Vygotsky, L. (1962). Thought and language. Cambridge, MA: MIT.

Wegerif. R. (2007). Dialogic, Education and Technology: Expanding the Space of Learning. New York: Springer-Verlag.

Wortham, S. (2003). Accomplishing identity in participant-denoting discourse. Journal of Linguistic Anthropology, 13, 1-22. 